\title{
CONSIDERACIONES ACERCA DE LOS CRITERIOS DE UNIDAD DE ACCIÓN EN LA RECIENTE JURISPRUDENCIA PENAL DE LA CORTE SUPREMA (2011-2012)*
}

\section{GONZALO BASCUR RETAMAL**}

\section{1) INTRODUCCIÓN}

\section{(1.1.) Problema analizado}

Como afirma Marwald, la abstracción conceptual propia de los tipos penales impide per se determinar cuántos actos (en sentido prejurídico) representan una sola realización típica ${ }^{1}$. Sin perjuicio de ello, existe consenso de que bajo una reconstrucción racional de los elementos de la ley penal, no resulta admisible una interpretación extremadamente formalista que implique una correlación estricta entre el número de actos y el número de injustos ${ }^{2}$. Por el contrario, se comparte ampliamente la opinión de que por diversas consideraciones valorativas, determinados supuestos de hecho, integrados por una pluralidad de actos, deben ser estimados jurídicamente como un solo delito.

El presente texto analiza cuáles de estas razones de unificación son consideradas por la Excma. Corte Suprema, a partir de una revisión de la doctrina jurisprudencial emanada de la Sala Penal correspondiente al período 2011-2012. Para ello, se ha optado por seleccionar los fallos donde el factum brutum sujeto a revisión evidencia una situación controvertida por los recurrentes (o eventualmente controvertible), a partir del instrumental dogmático propio de la teoría de la unidad y pluralidad de delitos. Todo lo anterior con la pretensión de identificar lineamientos generales acerca de un problema jurídico de tremenda relevancia práctica que, hasta donde hemos conocido, ha pasado mayormente desapercibido en el medio local.

Este trabajo ha sido redactado en el contexto del proyecto FONDECYT Número 11121313, titulado "Tratamiento penal de la reiteración delictiva: Sistematización y criterios distintivos relevantes de considerar", dirigido por el Dr. Francisco Maldonado Fuentes, a quien debo mi agradecimiento por su siempre valiosa orientación.

** Abogado. Licenciado en Ciencias Jurídicas por la Universidad de Talca. Correo electrónico: gonzalo_bascur@hotmail.com

1 Sanz Morán, Ángel (1986) El Concurso de Delitos. Aspectos de Politica Legislativa. Valladolid: Editorial Secretariado de Publicaciones Universidad de Valladolid. 278 pp. p. 114.

2 García Alberó, Ramón (1994) "Sobre la denominada unidad natural de acción". Anuario de Derecho Penal y Ciencias Penales. Tomo XLVII Fascículo II. pp. 211-239. pp. 212-213. 


\section{(1.2.) SUBSUNCIÓN, UNIDAD DE ACCIÓN Y PROHIBICIÓN DE EXCESO}

En el contexto de adjudicación de responsabilidad penal, la subsunción constituye el primer estadio lógico para el aplicador del derecho, localizado dogmáticamente en la escala categorial de la tipicidad ${ }^{3}$. Lo relevante en este punto $-y$ en lo que aquí interesa- es identificar al principio constitucional de proporcionalidad como límite para tal operación, concretado en el contexto del derecho penal sustantivo bajo la denominada prohibición de doble valoración o principio ne bis in idem ${ }^{4}$. Sobre este presupuesto y tratándose de un solo tipo penal aplicable al factum brutum objeto de valoración, el operador jurídico debe identificar o contabilizar el número de veces (o instancias) que ha sido realizado el mismo tipo delictivo 5 .

Si el resultado interpretativo arriba a la configuración de un solo objeto de subsunción, se habla entonces de una situación de unidad de acción $^{6}$; si por el contrario se obtiene un resultado inverso, se verifica el supuesto de hecho de un concurso real de delitos de carácter homogé$n e 0^{7}$. En términos más tradicionales, lo anterior se corresponde con la distinción acerca de una situación de unidad o de pluralidad de delitos, nomenclatura relativa al estudio de la teoría de la unidad de acción y la teoría del concurso de delitos ${ }^{8}$, respectivamente. Por ende, las consecuen-

3 En esta linea, Kindhauser explicita que la acción jurídico-penal debe entenderse como un constructo interpretativo dependiente de una descripción (el tipo penal), de la cual se constituye como una entidad teleológicamente irreductible, es decir, cuya entidad individual se constituye (en forma inicial) exclusivamente por los elementos conceptuales de la tipicidad: "en consecuencia, antes de la tipicidad solo puede existir como factum brutum una conducta, la cual se interpreta como un hecho punible concreto solo mediante los predicados del delito respectivo". Kindhauser, Urs (2012) "Acerca del concepto jurídico penal de acción". Cuadernos de Derecho Penal. Año 4, Número 7. pp. 11-41. pp. 20-31.

4 El principio ne bis in idem implica que considerar dos veces la misma propiedad de un hecho para fundamentar o agravar la sanción a ser impuesta sobre una persona constituye (sobre la base de esta comprensión) una contravención de esa prohibición de exceso. Así, en el caso de la verificación de la tipicidad, el principio se traduce en la operatividad de los criterios de unidad de acción; por otra parte, en la etapa de la determinación de la pena, se concreta en la (eventual) configuración de un concurso aparente de delitos. Mañalich RaFFo, Juan Pablo (2011) "El principio ne bis in idem en el derecho penal chileno". Revista de Estudios de la Justicia. Año 10, Número 15. pp. 139-169. pp. 142-151.

5 Mañalich Raffo, Juan Pablo (2005) "El concurso de delitos: Bases para su reconstrucción en el derecho penal de Puerto Rico”. Revista Jurídica UPR, Volumen 74. pp. 1021-1211. pp. 1096-1111.

6 El concepto jurídico-penal de acción resulta entendido en el marco de este artículo, al solo efecto de facilitar la exposición, como sinónimo de delito (injusto culpable). Por ende el término unidad de acción comprende tanto infracciones culpables a normas prohibitivas (delitos de acción) como a normas de mandato (delitos de omisión).

García (1994) 211-216. SANZ (1986) 113-114.

Asumiéndose que la teoría del concurso se refiere al estudio de las reglas sobre determinación legal de la pena para el castigo de dos o más delitos en el marco de un mismo proceso penal. 
cias uno u otro resultado son cruciales en la práctica: una situación de unidad de acción conlleva (solo) la aplicación de la respectiva norma de sanción establecida en la parte especial; una situación de concurso real homogéneo plantea, alternativamente, o la aplicación de la norma concursal (de sanción) de acumulación material del art. $74 \mathrm{CP}$ o bien el régimen de acumulación jurídica del art. $351 \mathrm{CPP}$.

La forma más difundida de ordenación de los criterios que conforman la teoría de la unidad de acción, predominante en la doctrina comparada, se basa en tres categorías diferenciadas a partir del parámetro valorativo que subyace a su formulación ${ }^{10}$ : (i) la unidad típica de acción, basada en la descripción (formal) del concreto tipo delictivo; (ii) la unidad natural de acción, basada en una articulación valorativa (material) del injusto en atención a la concreta manifestación situacional ${ }^{11}$ del respectivo tipo delictivo, y; (iii) la unidad por continuación (o también denominado delito continuado), basada en la intensa conexión objetiva-subjetiva presente entre los actos, expresada a través de los siguientes requisitos comúnmente aceptados ${ }^{12}$ : (a) unidad de dolo ${ }^{13}$; (b) unidad de sujeto activo;

$9 \quad$ El art. $74 \mathrm{CP}$ implica la mera sumatoria de las penas individuales; el art. $351 \mathrm{CPP}$ requiere la selección de una pena-base, que puede ser (según el caso) cualquiera de las sanciones involucradas o la que en concreto aparezca como más grave (dependiendo si presentan igual o diversa entidad de pena), que debe ser aumentada en uno o dos grados bajo el parámetro del número de realizaciones atribuidas. En la práctica, uno u otro régimen se aplican bajo la consideración jurisprudencial y dogmática (con fuerza de regla) de mayor favorabilidad para el imputado, de acuerdo a la interpretación dominante del inc. IV del art. 351 CPP (y previo art. 509 CDPP). Etcheberry Orthusteguy, Alfredo (1999) Derecho Penal: Parte General. $3^{a}$ ed. Santiago: Editorial Jurídica de Chile. T. II. 269 pp. p. 119.

10 La clasificación reseñada es propia del derecho comparado. Mañalich (2005) 1027 1034. Roxin, Claus (2014) Derecho Penal Parte General. Especiales formas de aparición del delito. Traducción de Diego Manuel Luzón-Peña (director). Navarra: Editorial Aranzadi, T. II, 1069 pp., pp. 943-962, pp. 1025-1034. Para una revisión sintetizada del panorama en el medio nacional: Couso Salas, Jaime (2011). "El régimen concursal en el derecho chileno. Tratamiento doctrinario y jurisprudencial". En Couso Salas, Jaime; Hernández Basualto, Héctor (directores): Código Penal Comentado: Libro Primero (arts. $1^{\circ}$ a $105^{\circ}$ ) Doctrina y Jurisprudencia. Santiago: Editorial LegalPublishing. 766 pp. pp. 625-681.

11 Escuchuri Aisa, Estrella (2004) Teoría del concurso de leyes y de delitos: Bases para una revisión crítica. Granada: Editorial Comares. 478 pp. pp. 388-391. Asimismo: García (1994) 222-224; SANZ (1986) 129-132.

12 Para una síntesis de los requisitos del delito continuado, véase: Oliver Calderón, Guillermo; Rodríguez Collao, Luis (2009) "Aplicabilidad de la figura del delito continuado en los delitos sexuales. Comentario a un fallo". Revista de Derecho Universidad Católica del Norte. Año 16 Número 1. pp. 251-264. pp. 254-256

13 En forma muy generalizada, actualmente la unificación subjetiva se construye a partir de dos modelos principales: (i) la teoría del dolo global o preconcebido (de origen italiano), consistente en una expansión del dolo típico a los posteriores actos sucesivos, en forma previa a la primera ejecución y; (ii) la teoría del dolo continuado o alternación (de origen alemán), apelativa a un déficit volitivo asimilable a un presupuesto de inexigibilidad, en el sentido de que la resolución criminal se actualizaría frente a circunstancias equivalentes ante las cuales el interviniente habría de ceder o alternar en forma contingente. Maurach, Reinhart; GösSel, Karl-Heinz; Zipf, Heinz (1995) Derecho Penal: Parte General. Formas de Aparición del 
(c) unidad espacio-temporal de realización; (d) unidad de bien jurídico afectado (y relativa similitud en las formas de ataque) y, (e) unidad de sujeto pasivo tratándose de bienes jurídicos personalísimos (no así en caso de bienes jurídicos patrimoniales) ${ }^{14}$.

Desde un punto de vista práctico, es posible afirmar que los criterios de unidad natural de acción y unidad por continuación presentan el mayor nivel de rendimiento considerando especialmente que, a diferencia de la unidad típica de acción, su parámetro de unificación no es de carácter concluyente, vale decir, limitado a la descripción formal del hecho típi$\mathrm{co}^{15}$, sino que resulta contingente ${ }^{16}$, pues se refiere a la valoración del concreto factum brutum a subsumirse en la norma, generando entonces la posibilidad de graduar el preciso contenido de injusto del hecho. Es por ello tales criterios son denominados alternativamente como unidades típicas de acción en sentido amplio ${ }^{17}$, recayendo tal ampliación en la posibilidad de que el contenido de antijuridicidad material de los actos parciales pueda ser interpretado como una sola instancia de menoscabo global al bien jurídico. Esta evaluación gradual se fundamentaría en que la pluralidad de actos solo vendría a constituir un aumento cuantitativo del mismo contenido de injusto ${ }^{18}$, por lo que a partir del marco unitario de una misma afectación del bien jurídico, se podría contener u absorver el contenido lesivo de diversos actos que no resulten expresivos de un aliud de injusto digno de castigo o valoraciones independientes ${ }^{19}$. Lo central de este pará-

Delito y las Consecuencias Jurídicas del Hecho. Traducción de Jorge Bofill Genzsch. Buenos Aires: Editorial Astrea. T. II. 1064 pp. pp. 538-548. Novoa Monreal, Eduardo (2005) Curso de Derecho Penal Chileno. Parte General. $3^{\text {a }}$ ed. Santiago: Editorial Jurídica de Chile. T. II. 477 pp. pp. 236-241.

14 Couso/Hernández (2011) 637-642. Besio Hernández, Martín (2012) "El delito continuado en el sistema penal chileno. Criterios y tendencias”. Razonamiento Penal. Año 1, No 2, pp. 117-147, pp. 118-145.

15 Suelen considerarse las estructuras típicas de varios actos (o delitos complejos); los delitos permanentes; los delitos habituales; los delitos con pluralidad de acciones; los delitos de tipicidad reforzada (o tipicidad mixta-alternativa) y los delitos de emprendimiento. Couso/HernánDEZ (2011) 637-642.

16 García (1994) 218-221. Sanz (1986) 128. Por lo que puede afirmarse que los criterios de unidad de acción operan como equivalente funcional (en sede de tipicidad) al principio de consunción, propio del contexto del concurso aparente de delitos. MañAlich (2005) 11241126. En términos (materialmente) similares: García (1994) 218-221; SANZ (1986) 128.

17 Escuchuri (2004) 388. SANZ (1986) 130.

18 García (1994) 218-222. SANZ (1986) 130. En nuestro medio, se inclinan sobre esta base material de unificación: Garrido Montt, Mario (2003) Derecho Penal: Parte General. No-

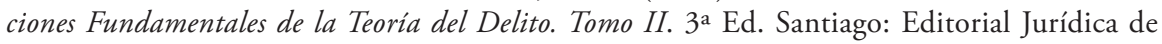
Chile. 369 pp. pp. 337-338. Politoff Lifschitz, Sergio; Matus Acuña; Jean Pierre, Ramírez Guzmán, María (2004) Lecciones de Derecho Penal Chileno: Parte General. 2a Edición. Santiago: Editorial Jurídica de Chile. 613 pp. p. 445.

19 Roxin (2014) 950. De esta forma, los criterios de unidad típica de acción siempre constituirán el primer eslabón de valoración unitaria. Por ejemplo, un delito con descripción de pluralidad de acciones (o de tipicidad mixta-alternativa) como el tráfico ilícito de pequeńas cantidades de estupefacientes (art. 4 Ley 20.000), que inicialmente ya unifica típicamente 
metro de unificación entonces es la flexibilidad que otorga al intérprete ${ }^{20}$, pues al reflejar que las expectativas normativas de la norma de conducta rigen situacionalmente, permitiría una valoración más prolija del desvalor del hecho a partir de la concreta manifestación de la infracción ${ }^{21}$.

Para los operadores jurídicos, las consideraciones previas evidencian un potencial de rendimiento argumentativo que no debiera ser omitido con tanta ligereza o simplemente darse intuitivamente por presupuesto en la discusión de fondo. Esto porque a diferencia del relativo consenso acerca de los (no por ello menos dúctiles) requisitos de configuración de un delito continuado, no se puede predicar idéntica claridad en los casos de unidad natural de acción.

Sintéticamente, esta categoría dogmática agrupa dos conjuntos de situaciones: (i) realizaciones sucesivas del tipo, consistentes en una progresión de actos de menor intensidad que finalmente llegan a la consumación más grave de un mismo delito (como por ejemplo una sucesión de

diversos actos como una sola realización, puede ser ampliado cuantitativamente a partir del segundo nivel que implica una realización iterativa (como operación criminal) considerando la estrechez espacio-temporal por períodos de tiempo bastante más prolongados que un delito cuya descripción formal suponga una situación inversa (como el acceso carnal o la causación de daños a la propiedad). Si a ello se adiciona la consideración de que el bien jurídico protegido en el ejemplo es de naturaleza colectiva, la posibilidades interpretativas podrían aún expanderse sin que aquello constituya una evasión de las reglas sobre concurso real. Se atribuye a MAIWALD la ordenación de los requisitos propios de la unidad natural de acción: (i) contexto espacio-temporal unitario; (ii) aumento meramente cuantitativo del injusto típico; (iii) motivación unitaria (la que entendemos comprendida como las posibilidades de control cognitivo y volitivo de la acción por el agente a título de dolo o culpa). EscuchURI (2004) 388-393; SANZ (1986) 130-131. El hecho de que toda realización admita ser parcelada en sucesivos estadios necesarios para la comisión del delito, no puede ser relacionada con el dolo típico pues reflejaría una comprensión naturalística de la acción que llevaría al absurdo de que toda inervación muscular justificase la apreciación de un concurso real. La frontera entre una misma ejecución y la reanudación como nueva infracción solo puede ser definido a partir de una apreciación valorativa. García (1994) 222-223. Análogamente GARRIDO fundamenta la unidad de acción a partir de consideraciones normativas, que denomina jurídica respecto a los casos ya señalados como unidad natural, a partir del principio (en su formulación roxiniana) del ámbito de protección de la norma, entendido como posibilidad de captar formas de ataque a partir del sentido de protección de cada tipo, complementado por la finalidad que dirige y orienta la acción (dolo). GARRIDo (2003) 337-339. En nuestro medio, se manifiestan desde una perspectiva contraria, descriptiva y centrada en valoraciones subjetivas de corte psicologicistas y fenomenológicas: CuRY URzÚA, Enrique (2005) Derecho Penal. Parte General. 7a Edición. Santiago: Ediciones Universidad Católica de Chile, 812 pp., pp. 650-651. Asimismo: EтcheberRy (1999) 110.

20 Esta flexibilidad del criterio de la unidad natural de acción se emparenta con su propia terminología, de ahí que lo natural deba entenderse en sentido normativo, como una valoración inclusiva de los actos individuales, por contraposición a la acción en sentido natural, es decir, como movimiento corporal o su ausencia, en tanto formas mínimas de comportamientos penalmente relevantes. Mañalich (2005) 1029, 1031. El concepto provendría de la jurisprudencia alemana donde solía apelarse a una interpretación unitaria de los actos a partir de "la normal concepción de la vida" o "según un modo natural de ver las cosas". Roxin (2014) 949-950. 
tentativas fallidas) y; (ii) realizaciones iterativas del tipo, consistentes en la repetición de acciones típicas dentro de un contexto de ejecución potencialmente considerable como unitario ${ }^{22}$.

En atención a los supuestos de hecho más relevantes de la jurisprudencia revisada, cuya selección obedece a su rendimiento para operativizar alguna las categorías de unidad de acción señaladas, hemos debido centrar exclusivamente la atención en los casos de delito continuado y unidad iterativa de acción.

Las sentencias analizadas se han agrupado a partir de los respectivos objetos jurídicos afectados: (i) delitos contra intereses asociados a la sexualidad; (ii) delitos contra intereses patrimoniales y; (iii) delitos contra diversos intereses protegidos (o realizaciones pluriofensivas).

\section{2) JURISPRUDENCIA}

\section{(2.1.) DELITOS CONTRA INTERESES ASOCIADOS A LA SEXUALIDAD}

En la causa (1) Rol No 3065-2011, el Octavo Juzgado del Crimen de San Miguel condenó a un sujeto por el delito de estupro (art. 363 No $2 \mathrm{CP}$ ) en carácter de reiterado, es decir, en relación de concurso real de delitos, por hechos delictivos ocurridos en fechas indeterminadas desde el 21 de octubre de 2004 hasta el 16 de junio de 2005. La pena impuesta fue de seis años de presidio mediante la aplicación de la regla del art. 509 CDPP, en régimen efectivo de cumplimiento ${ }^{23}$. La Corte de Apelaciones de San Miguel, a instancia de la defensa, modificó la calificación jurídica de los hechos acogiendo la teoría del delito continuado, lo que provocó una notable disminución de la intensidad de la condena a una pena de cinco años de presidio en régimen de libertad vigilada.

Ante ello, el recurrente alegó infracción de derecho al no apreciarse una situación de concurso real, sobre la base de dos consideraciones (implícitas) ligadas a la configuración del injusto (considerando primero): (i) la separación espacio-temporal entre los hechos impediría constatar una sola ejecución continuada, pues en cada oportunidad se habría colmado el contenido de antijuridicidad del estupro determinando unidades delictivas (tentativa-terminación) independientes y; (ii) no resulta correcto desde el objeto tutelado (indemnidad sexual) hablar de una intensificación cuantitativa de un mismo injusto, pues la entidad inherente a cada ejecución implicaría, en estos delitos, un grado de lesividad justificatorio de la conformación de un desvalor autónomo punible individualmente ${ }^{24}$.

\footnotetext{
22 Mañalich (2005) 1031-2032. Escuchuri (2004) 388-393. Roxin (2014) 949-956.

23 Corte Suprema. 9 de marzo de 2011. Rol No 3065-2010. "Contra Osvaldo Repol Garrido".

24 CS. Rol No 3065-2010, pp. 2-3.
} 
Si bien la pretensión se rechazó en virtud de la exigencia procesal de la trascendencia del vicio invocado, pues la concurrencia de dos atenuantes habría permitido anular la exasperación en un grado que significa aplicar el art. 509 CDPP, la CS. declaró adicionalmente (en su considerando sexto) que en los hechos no se configuraría una situación de delito continuado, asumiendo que para su eventual admisión debería aplicarse la tesis basada en la violación necesariamente fraccionada de la misma norma de deber sostenida por CuRY ${ }^{25}$, en virtud de dos consideraciones: (i) el hecho de que la víctima haya dado a luz a un niño en el tiempo intermedio evidenciaría al menos una fecha exacta, aplicando la presunción de derecho del art. $76 \mathrm{CC}^{26}$ y; (ii) la naturaleza del injusto (afección de un bien personalísimo) tornaría improcedente la necesidad de fraccionamiento de la infracción de la norma ${ }^{27}$.

El primer argumento se liga al discutible requisito de adicionar al concurso real la exigencia procesal de certeza exacta de cada ejecución ${ }^{28}$ (lo que correlativamente, en delitos donde consta fehacientemente cada acto ejecutivo -como determinadas estafas u apropiaciones indebidas-, necesariamente implicaría su rechazo, circunstancia que no se verifica, como se verá); mientras que el segundo argumento, se vincula a la perspectiva que el tribunal asume para dotar de contenido al desvalor de resultado como parámetro de merecimiento de pena, reflejo del concepto mismo de injusto a efecto de trazar el límite del bien jurídico para ser lesionado gradualmente (aumento cuantitativo) sin configurar una situa-

25 Sintéticamente, para Cury el delito continuado es un problema normativo (abandonando su inicial propuesta de corte ontológica propuesta en 1959) que denomina la violación necesariamente fraccionada de la misma norma de deber, concretado bajo una forma de unidad jurídica de acción. El elemento unificador de los eventos se ubicaría en el plano de la antijuridicidad material, de forma que producto de la contingencia en el momento de la ejecución del delito, el agente se vería compelido a ejecutar en forma fraccionada su representación (subjetiva) originaria. La fórmula no deja de ser novedosa, pues implica descartar las situaciones de preordenación delictiva (en que no habría necesidad sino planificación), pero acota notablemente las situaciones que la doctrina tradicional agrupa bajo el delito continuado, si ha de tomarse en serio su justificación (por ejemplo, no habría continuación en la planificación de una apropiación indebida de parte de un cajero hasta el momento en que fuese descubierto, o en la mayoría de los delitos de connotación sexual). Cury (2005) 656-658.

26 Considerando sexto: "que como consecuencia del mismo, se produjo el nacimiento de un menor, el 13 de noviembre de 2005, fecha de la que se puede colegir que la época de la concepción precedió al nacimiento en no menos de ciento ochenta dias cabales, y en no más de trescientos, contados hacia atrás, desde la medianoche en que principió el día del parto (...) circunstancias que desde ya, nos permiten concluir que el delito se habría cometido, a lo menos, en dos oportunidades distintas y claramente independientes entre sí, con sus propias circunstancias y desvinculadas una de otra". CS. Rol No 3065-2010, p. 7.

27 CS. Rol No 3065-2010, pp. 4-9.

28 Besio (2012) 138-141. Couso/Hernández (2011) 644-646. Inclusive, la aplicación del art. $76 \mathrm{CC}$ en sede penal (a pesar del principio de unidad del ordenamiento jurídico) contravendría la prohibición constitucional del art. 19 No 3 inciso VI CPR al presumirse (de derecho) un elemento de la condena tan elemental como el acto ejecutivo. 
ción de reiteración (aumento cualitativo). En este caso, la CS., indirectamente, adhiere a un concepto personal de objeto jurídico, evaluando su afectación desde el perjuicio irrogado al sustrato empírico del mismo ${ }^{29}$, lo que implicaría per se descartar la aplicación de la teoría del delito continuado en el contexto de atentados contra diversos sujetos pasivos tratándose de bienes jurídicos personalísimos.

En el caso (2) Rol No 2576-2011, el Quinto Tribunal Oral en lo Penal de Santiago condenó a dos imputados por los delitos de abuso sexual (art. 366 inc. I CP) y producción de material pornográfico infantil (art. 366 quinquies CP), ocurridos entre los meses de abril a julio de 2007. Los hechos consistieron en que X (madre de la víctima) e Y (conviviente de $\mathrm{X}$ y operador de la cámara) filmaron a la ofendida mientras dormía, realizándole tocaciones en los genitales y senos durante tres ocasiones, con la sola excepción de que Y solo participó en el abuso sexual una vez. La defensa recurrió de nulidad -en el aspecto que aquí interesa- por errónea aplicación del derecho al determinar la existencia de un concurso real, solicitando que se considere un delito continuado sobre las tres instancias de realización de ambos delitos, cuya calificación jurídica que alternativamente propuso, para cada ocasión, (i) como un concurso aparente (de admitir que los tipos comparten idéntico bien jurídico protegido) o bien (ii) como un concurso ideal (reconociendo distintos objetos tutelados en una y otra norma) ${ }^{30}$. La CS. acogió parcialmente la pretensión, efectuando una distinción que merece un análisis más detallado

En primer lugar, se reconoció una relación de concurso medial entre cada una de las tres realizaciones (conjuntas) de X, pero rechazando -sin fundamentación explícita- la tesis del delito continuado ${ }^{31}$, a favor de

29 Considerando sexto: "toda vez que, atendida la naturaleza del tipo penal y el bien jurídico protegido -la indemnidad sexual de la adolescente-, resulta improcedente suponer que conforme a la propia representación del autor, la violación de la norma que penaliza la conducta de quien accediere carnalmente por vía vaginal, anal o bucal a una persona menor de edad, pero mayor de catorce años, no era posible consumarla sino en forma fraccionada". CS. Rol No 3065-2010, p. 7.

30 Corte Suprema. 11 de mayo de 2011. Rol No 2576-2011. "Contra Sebastián Segundo Araya Soto y Sandra Marcela Yáñez Yáñez”. pp. 1-11 (sentencia de nulidad).

31 La única remisión explícita se encuentra en el voto disidente del abogado integrante Pozo Silva, quien señala que la pluralidad de actos es natural al delito de abuso sexual " tal como al igual una lesión puede inferirse a través de un solo golpe, como también a través de una secuencia de ellos", por lo que debería apreciarse un delito continuado entre las tres ocasiones, cada una constitutiva de una situación de concurso ideal (por intersección parcial de las acciones ejecutivas). CS. Rol No 2576-2011, pp. 4-5 (sentencia de reemplazo). Si bien en lo segundo la consideración es acertada (el tratamiento bajo el art. $75 \mathrm{CP}$ ), existe un profundo error conceptual en toda la cadena argumentativa posterior, pues tal adjudicador intenta conciliar una situación de unidad de acción en sentido estricto (la unidad natural precedente), con tres variantes subjetivas de fundamentación del delito continuado (incompatibles entre sí): (i) la teoría del dolo global (a partir del desarrollo efectuado por Mir Puig, como dolo preconcebido); (ii) con la teoría del dolo continuado (como actualización subjetiva contingente ante circunstancias motivadoras análogas, similar a un déficit motivacional) y; (iii) con la 
considerar un concurso real tratado mediante la regla del art. $351 \mathrm{CPP}$, lo que resultó, habida la compensación racional de circunstancias modificatorias, en una pena de cinco ańos y un día de presidio en régimen de cumplimiento efectivo. Pero respecto a Y se produce una situación inversa. A pesar de la acreditación procesal de su intervención en tres ocasiones a título de camarógrafo (considerando undécimo), como reflejo de una evidente situación de concurso real según lo manifestado en el caso (1) por la CS., el tribunal lisa y llanamente declaró que el conviviente " $h a$ resultado responsable de un delito de abuso sexual y del delito consumado de material pornográfico infantil' 32 , omitiendo la aplicación del régimen del concurso real y determinando la pena solo mediante la regla del art. 75 CP (concurso medial), lo que derivó en una condena de tres ańos y un día de presidio en régimen alternativo de libertad vigilada ${ }^{33}$.

Así, la configuración implícita de una situación de unidad de acción para $\mathrm{Y}$ en perjuicio de $\mathrm{X}$, evidencia una relativización de la aplicación de la ley penal a partir de consideraciones ajenas al reproche (estrictamente) jurídico, que comprometen seriamente un mínimo de coherencia en el desiderátum respecto a la garantía constitucional de la igualdad ante la ley. Empero, cabe apuntar que de haberse extendido tal consideración a la madre, el marco penal habría sido compatible con los -en ese momento vigentes- regímenes alternativos de la Ley No 18.216. En este sentido, la exasperación del art. $351 \mathrm{CPP}$ permitió, formalmente, eludir una fundamentación (de carácter material) para la denegación tales beneficios sobre X.

\section{(2.2.)DELITOS CONTRA INTERESES PATRIMONIALES}

En el caso (3) Rol No 10150-2011, la Corte de Apelaciones de Puerto Montt confirmó la pena impuesta a X de cinco años y un día de presidio por el delito de evasión tributaria ${ }^{34}$ mediante aumento doloso de crédito fiscal, tipificado en el art. 97 No 4 inc. II ${ }^{35}$ del Código Tributario,

posición (formalmente) normativa defendida por CuRY (la valoración unitaria del injusto) a partir de su propia constatación acerca de la insuficiencia material de las dos formulaciones previas. Sin perjuicio de ello, la sanción de X (de haberse seguido esta tesis interpretativa) habría resultado en una pena de cuatro ańos de presidio, debiendo justificarse la denegación de los beneficios de la Ley No 18.216 .

32 CS. Rol No 2576-2011, p. 2 (sentencia de reemplazo).

33 CS. Rol No 2576-2011, pp. 3-4 (sentencia de reemplazo).

34 Corte Suprema. 11 de abril de 2012. Rol No 10150-2011. "Contra Roselda Janett Toledo Soto". pp. 1-4.

35 Artículo 97 No 4 inc. II: "Los contribuyentes afectos al Impuesto a las Ventas y Servicios u otros impuestos sujetos a retención o recargo, que realicen maliciosamente cualquiera maniobra tendiente a aumentar el verdadero monto de los créditos o imputaciones que tengan derecho a hacer valer, en relación con las cantidades que deban pagar, serán sancionados con la pena de presidio menor en su grado máximo a presidio mayor en su grado mínimo y con multas del cien por ciento al trescientos por ciento de lo defraudado”. 
en situación de concurso real tratado bajo la regla especial del art. 112 del mismo cuerpo legal ${ }^{36}$. Ante ello, la defensa recurrió de casación en el fondo alegando error de derecho al haberse desechado la configuración de un delito continuado. En este sentido, la pretensión se basó en que durante un lapso de tiempo no identificado, el que según se deduce, habría excedido más de un ejercicio comercial anual ${ }^{37}$, X adulteró documentación comercial con el doble objeto de rebajar impuesto a la renta y aumentar el crédito fiscal por impuesto al valor agregado, generando un perjuicio estatal de \$29.993.343 y \$18.345.998 por concepto de cada tributo, respectivamente.

La alegación es rechazada por el tribunal por razones estrictamente procesales, consistentes en el nivel de competencia que le otorga la causal invocada $^{38}$, en el sentido que - bajo la comprensión de la Corte- una relación concursal constituiría una cuestión de hecho y no de derecho.

Si bien no resulta alegado por el recurrente, puede asumirse que en situaciones de evasión fiscal la propia fenomenología delictiva implicaría una planificación dolosa correlativa al período de devengamiento de los impuestos, circunstancias que tanto a nivel de injusto del comportamiento y del resultado (la lesión del patrimonio fiscal cuando se liquida el total del tributo), facilitarían la apreciación de los requisitos del delito continuado. En relación a esto, el fallo resulta interesante porque en el considerando noveno se aclara, adicionalmente a lo alegado por la defensa, que

36 Cabe consignar que el art. 112 inciso I CT señala que en los casos de reiteración de delitos tributarios, se debe aplicar la pena de ellos estimándolos como un solo delito, posteriormente exasperada según lo dispuesto en el art. 351 CPP. La lógica operativa de esta regla especial, en consideración al principio de interpretación útil, no ha sido clarificada en el medio local. En la práctica jurisprudencial, contradiciendo el axioma precitado, la norma se aplica como si se tratase directamente del art. $351 \mathrm{CPP}$.

37 El concepto de ejercicio comercial anual o año fiscal comprende un período temporal de doce meses que constituye la unidad jurídica para el devengamiento de ciertas obligaciones tributarias (en particular el impuesto a la renta), a cuyo vencimiento se calcula y liquida el monto final del impuesto. La aclaración es relevante en atención al inciso III del art. 112 $\mathrm{CT}$, que establece que existirá reiteración (bajo su concepción dominante como sinónimo de concurso real) cuando se incurra en las conductas en más de un ejercicio comercial anual. Como se aprecia, se trata de una (excepcional) declaración formal del legislador acerca del límite de la unidad (típica) de acción aplicable a todas las especies de delitos tributarios.

38 Así, el considerando octavo señala que "Que en lo relacionado con el recurso de nulidad instaurado por la defensa de la condenada, resulta evidente que en los términos en que ha sido planteado implica modificar el escenario fáctico establecido por los juzgadores del grado. Empero, como reiteradamente se ha declarado por esta Corte, los hechos son inamovibles para este tribunal de casación”. CS. Rol No 10150-2011, pp. 5-6. Pero la pretensión de la defensa, según consta en el mismo fallo, recayó sobre un punto de valoración estrictamente jurídico, tal como afirma el considerando segundo: "(la defensa) solicita en lo petitorio el rechazo de la agravante (en el sentido de lo perjudicial que resulta la aplicación del sistema de exasperación y no literalmente como circunstancia modificatoria agravante especial de responsabilidad) contemplada en el artículo 112 del Código Tributario que califica como reiterados los delitos pesquisados". El paréntesis es nuestro. CS. Rol No 10150-2011, pp. 3-4. 
la configuración del supuesto de hecho del art. 112 CT, es decir, cuando la ejecución delictiva logre sobrepasar un ejercicio comercial anual, necesariamente implicaría considerar la existencia de un concurso real de delitos.

Lo anterior no puede ser avalado. Un mínimo de coherencia del tribunal acerca de su propia adopción de la teoría del delito continuado para (en otros casos) negar un concurso real homogéneo, implica necesariamente que respecto a los delitos fiscales tal construcción deba ser considerada solo en situaciones en que se sobrepase la unidad jurídico-tributaria del ejercicio comercial anual, pues lo contrario tornaría superflua la definición de unidad (típica) de acción establecida en el inc. III del art. 112 CT.

En el caso (4) Rol No 7266-2011, la Corte de Apelaciones de San Miguel confirmó la condena del Décimo Juzgado de Crimen respectivo en contra de cuatro imputados por los siguientes delitos: (i) cuatro penas de 61 días de presidio cada una para W, X e Y, por los delitos de falsificación y uso de boletas y sello de particular (art. $185 \mathrm{CP}^{39}$ ) y estafa calificada (art. 468 en relación al art. 467 No $3 \mathrm{CP}$ ), en relación de concurso medial entre sí pero en carácter de reiterados por aplicación de la regla de acumulación material del art. $74 \mathrm{CP}$ y; (ii) una pena única de 61 días de presidio para $Z$ por un delito de estafa calificada. Si bien la parte querellante dedujo recurso de casación en el fondo en relación a la calificación del delito más grave a efecto del art. $75 \mathrm{CP}$ para obtener una mayor cuantía respecto a la multa ${ }^{40}$, en lo pertinente resulta llamativa la mantención de la relación concursal tanto por el querellante como por los tribunales de alzada y casación.

Los hechos consistieron en que W, X e Y forjaron boletas de honorarios y comprobantes particulares material e ideológicamente falsificados, que luego $Z$ hizo valer en su calidad (real) de afiliada a Isapre Golden Cross a título de crédito los días 5, 8, 9 y 13 de noviembre de 2001, obteniendo como reembolso total la suma de $\$ 185.189^{41}$.

Se trata de un caso llamativo pues el tribunal admite la configuración de un concurso de concursos, en este caso un concurso real entre cuatro

39 Artículo 188: "El que falsificare boletas para el transporte de personas o cosas, o para reuniones o espectáculos públicos, con el propósito de usarlas o de circularlas fraudulentamente, y el que a sabiendas de que son falsificadas las usare o circulare; el que falsificare el sello, timbre o marca de una autoridad cualquiera, de un establecimiento privado de banco, de industria o de comercio, o de un particular, o hiciere uso de los sellos, timbres o marcas falsos, sufrirá la pena de presidio menor en cualquiera de sus grados y once a veinte unidades tributarias mensuales".

40 Corte Suprema. 19 de abril de 2012. Rol No 7266-2011. "Contra Lorena Sánchez Álamos, Leopoldo Díaz Canales, Cristián Urtubia Fuentes, Jaime Silva Ortiz”. pp. 1-6 (sentencia de invalidación de oficio)

$41 \quad$ CS. Rol 7266-2011, p. 4 (sentencia de invalidación de oficio). 
concursos mediales correlativos a cada día de presentaciones para reembolso, aunque solamente respecto a W, X e Y, pues tal consideración no resulta materialmente extensible a $Z$, en cuya condena se produce un salto lógico digno de atención. Si bien la calificación jurídica efectuada por el tribunal de alzada le atribuyó a $\mathrm{Z}$ intervención exclusiva como "autora de cuatro delitos de estafa" 42 lo que fue confirmado por el tribunal de casación al declararla responsable "de los delitos reiterados de estafa" 43 , uno y otro fallo le aplican la pena única de 61 días de presidio, según el art. 467 No 3 CP (total del importe defraudado).

Como se aprecia, se trata de una situación expresamente declarada de concurso real pero sustancialmente tratada como situación de unidad de acción. En concreto, lo que podría subyacer a tal consideración favorable puede ligarse a la absolución obtenida por la defensa de $\mathrm{Z}$ en alzada, respecto a las operaciones de forjamiento (pero no de uso de tales instrumentos falsificados ${ }^{44}$ ), la que se vería expresada en una menor intensidad del merecimiento de pena en contraste a los procesados $\mathrm{W}, \mathrm{X}$ e $\mathrm{Y}$.

Por otra parte, en los casos (5) a (11) cabe constatar una homogénea linea jurisprudencial acerca de la calificación jurídica (unitaria) otorgada por el tribunal a una serie de realizaciones delictivas cuyo hilo conductor es el sistema de determinación de la pena basado en la cuantía del perjuicio patrimonial irrogado al sujeto pasivo, común a los delitos de estafa y otros engaños (art. $467 \mathrm{CP}$ ) y hurto (art. $446 \mathrm{CP}$ ).

En este sentido, en el caso (5) Rol No 1737-2010 la Corte confirmó la condena impuesta a X por el delito del art. 13 de la Ley No 17.322 de 1970 (apropiación indebida de cotizaciones previsionales) ${ }^{45}$, decisión que (para lo que aquí interesa) mantuvo la calificación jurídica del supuesto

42 CS. Rol 7266-2011, p. 1 (sentencia de invalidación de oficio).

43 CS. Rol 7266-2011, p. 2 (sentencia de reemplazo).

44 Este aspecto pasa desapercibido para los intervinientes pero habría resultado crucial al momento de la determinación de la pena. Si tanto para el tribunal a quo como de alzada existe un concurso real entre los delitos del art. 185 y el art. 468 CP (en el sentido de que un concurso medial es un tratamiento beneficioso para una situación especialmente valorada de reiteración), no debe olvidarse que la estructura típica del art. $185 \mathrm{CP}$ corresponde a un delito de tipicidad mixta-alternativa (o reforzada) -en este caso- expresiva de las modalidades de falsificación y uso de tales instrumentos. Obviando que esta constatación permitiría afirmar un concurso ideal entre ambas realizaciones (la intersección que implica la utilización de los documentos como uso y engaño respectivamente), la negación de un concurso aparente implicaría, además de que existe un interés tutelado distinto al patrimonio particular en el falseamiento de documentación estrictamente privada, la consideración de la autoría ejecutiva (de propia mano) de $Z$ respecto al delito del art. 185 (al menos en los términos del art. 15 No 1 CP) como (se reconoció) de la estafa calificada. Por ende, pareciera que ambos tribunales identifican el primer delito exclusivamente como forjamiento (descartando la utilización), desde un anclaje conceptual limitado al hecho empírico de la sola confección -al menos para excluir la responsabilidad de $\mathrm{Z}$ por el uso- pero admiten la extensión normativa de la coautoría a W, X e Y respecto a la estafa (para fundar un concurso real).

45 Se trata de un delito especial (como especie de la apropiación indebida genérica del art. 470 No $1 \mathrm{CP}$ ) en virtud del sujeto activo (empleador) y el objeto de ataque: el dinero provenien- 
de hecho como delito continuado establecida por la Corte de Apelaciones de Rancagua, por el monto total de fondos retenidos entre abril de 1999 a febrero de $2002^{46}$. A partir de un supuesto de hecho similar, en la causa (6) Rol No6991-2010 se mantiene la apreciación de un solo delito de apropiación indebida del art. $470 \mathrm{No} 1 \mathrm{CP}$, a pesar de recaer sobre cotizaciones previsionales ${ }^{47}$, realizado por el empleador de una constructora en forma ininterrumpida desde diciembre de 2002 hasta agosto de 2004, acarreando un perjuicio total de $\$ 11.838 .189$ sobre diversos trabajadores $^{48}$.

Uno y otro caso tienen aspectos dignos de considerar estrechamente ligados con la posibilidad de consideración unitaria. En la causa (6), al prescindir de una mención expresa al delito continuado, la calificación jurídica excedería las posibilidades de unificación en virtud de consideraciones valorativas (unidad natural de acción) a partir de una limitación propia de su contenido de injusto: si la forma de ataque consiste en la infracción de la obligación de declaración y pago por el empleador, la articulación valorativa del injusto propio de esta variante de fraude debe correlacionarse con la regulación general de tales deberes contenida en el D.L. No 3500 y la Ley No 17.322 (cuya lógica obedece a un sistema relativamente semejante de injusto a los delitos tributarios ya señalados $)^{49}$, la que restringiría la delimitación situacional de la ejecución a un mes calendario como unidad delictiva, a cuyo vencimiento necesariamente debería apreciarse una situación de reiteración (concurso real), salvo que expresamente se inste a la declaración de una situación de unidad por continuidad. El caso (5) subsana este inconveniente mediante tal constatación, aunque presenta un problema de legalidad (como se verá) al determinarse la pena sobre la base del monto total del perjuicio patrimonial (según el art. 467 No 2 y No 1 CP respectivamente).

Este segundo inconveniente se evidencia en los restantes casos asociados a delitos patrimoniales: en (7) Rol No 5790-2010, el Primer Juzgado del Crimen de Temuco aplicó directamente la pena del art. 467 inc. II $\mathrm{CP}$ al administrador de diversos locales de venta de harina pertenecientes

te de los descuentos realizados a título de cotizaciones de la remuneración de un trabajador (que no cabrían bajo el deber fiduciario de entregar o devolver del régimen común).

46 Corte Suprema. 14 de febrero de 2011. Rol No 1737-2010. "Contra Paulo Vial Munita". pp. 1-3.

47 Figura inaplicable pues el deber del agresor no recae en entregar o devolver, sino enterar en la institución de seguridad social respectiva el dinero descontado a efecto de abonarse a la cuenta de capitalización del trabajador afectado.

48 Corte Suprema. 30 de junio de 2011. Rol No 6991-2010. "Contra Alfonso Morandé Court". pp. 1-3.

49 La regla general del art. 19 inc. I D.L. No 3500 es que dentro de los 10 primeros días hábiles del mes siguiente a aquel en que se devengaron las remuneraciones, el empleador debe declarar y pagar las respectivas cotizaciones. El art. 22 de la Ley No 17.322 hace extensible tal deber a los dependientes del empleador que realicen tal función. 
a una empresa molinera, por múltiples actos de apropiación sobre parte de las recaudaciones diarias que depositaba en su cuenta bancaria personal, realizadas desde 1998 a 2000 por un total de $\$ 529.183 .926^{50}$; en la causa (8) Rol 6514-2012 se apreció una sola realización del delito de estafa calificada (art. $468 \mathrm{CP}$ ) castigada por el total del importe según el art. 467 inc. II CP, por la ejecución de una serie de actos fraudulentos (adulteración de documentos, simulación de contratos) para la obtención de reembolsos indebidos) efectuados por el X, Y e Z (gerente de operaciones, el jefe de cobranzas y contratista externo), en perjuicio de una empresa de leasing industrial desde mayo de 2000 a noviembre de 2001, por un total de $\$ 1.761 .138 .886^{51}$.

En ambas causas (7 y 8), para la calificación jurídica unitaria no se alude al delito continuado, bastando la referencia al nomen iuris respectivo, a diferencia del caso (9) Rol No 9521-2011 donde que se aplicó el art. 467 No 2 CP a X, Y e Z, trabajadoras de una pastelería, que desde 2003 hasta una fecha no determinada en el fallo, se apropiaron de recaudaciones diarias por determinadas ventas que no registraban como boletas sino que otorgando directamente a los clientes vales previamente confeccionados, los que finalmente sumaron una pérdida total de $\$ 2.033 .774$ para el establecimiento $^{52}$.

Finalizando este grupo de casos, en un sentido similar en la causa (10) Rol 7777-2011 se castigó a tres imputados bajo el título formal de reiteración de hurtos, mediante la aplicación directa del art. 446 inc. II CP por el total del valor de las especies expropiadas, a partir de la sustracción diaria realizada desde 1999 a 2001 de dinero en efectivo sobre las ventas de una distribuidora, ascendente a la suma de $\$ 1.440 .519 .199^{53}$, sin aplicación de la agravante del art. 447 CP (denominada hurto del dependiente) ni de la regla especial sobre reiteración de hurtos del art. $451 \mathrm{CP}$.

\section{(2.3.)DElitos CONTRA DiVERSOS INTERESES PROTEGidos (O REALIZACIONES PLURIOFENSIVAS)}

En esta categoría temática solamente se ha considerado una resolución, la que por su relevancia general ameritaría un detallado tratamiento independiente. En la causa (11) Rol No 6831-2012, se rechazaron los

50 Corte Suprema. 20 de enero de 2012. Rol No 5790-2010. “Contra Patricio Javier Juan José Kinzel Zurita”. pp. 1, 13-14 (sentencia de casación).

51 Corte Suprema. 3 de diciembre de 2012. Rol No 6514-2012. "Contra Mauro Nasser Salazar y otros". pp. 1-6.

52 Corte Suprema. 13 de marzo de 2012. Rol No 9521-2011. "Contra María Elisa Castro Bardales, Elizabeth Angélica Aravena Sanhueza, Paola Carolina Garrido Novoa”. pp. 1-5.

53 Corte Suprema. 16 de mayo de 2012. Rol No 7777-2011. "Contra Humberto Contreras Anguita y otros". pp. 1-2, 37. 
recursos de nulidad deducidos por el Ministerio Público, el querellante y el Servicio Nacional de Aduanas. Si bien el supuesto de hecho presenta numerosas particularidades transversales a toda la teoría general del delito, en lo que aquí interesa (más allá de tratarse del -hasta ahora- más importante caso de responsabilidad penal por el producto en la historia de Chile), el Tribunal Oral en lo Penal de San Bernardo condenó a tres imputados por una serie de acusaciones en el contexto del mediatizado caso "ADN-Nutricomp" 54 , que serán diferenciadas para efecto de su análisis.

Sintéticamente, los hechos consistieron (considerando octavo) en la comercialización del suplemento alimenticio $A D N$-Nutricomp por la empresa B. Braun Medical S.A., orientado para el tratamiento de personas con enfermedades ligadas a deficiencias nutricionales. En abril de 2007, producto de un error del jefe de control de calidad de la planta (W), el productor extranjero encargado de originar la materia prima habría introducido un nivel menor de potasio al requerido para los fines de las distintas líneas del producto ( $1 \%$ en vez del $100 \%$ de concentración informado en su rotulación). Los productos inician su comercialización masiva en junio de 2007, sin que el jefe de producción de la empresa (X) haya efectuado algún control de calidad posterior. En noviembre de 2007, W y X toman conocimiento de la errónea composición química del alimento y lo comunican al gerente general $(\mathrm{Y})$, quien decidió no retirar las partidas afectadas del mercado y no informar a la autoridad sanitaria, clientes ni proveedores, adoptando la medida de que la empresa, por sus propios medios, introdujera una dosis adicional del mineral a los futuros lotes. A su vez, se informa al gerente de exportaciones $(Z)$ de la situación, quien por orden de $\mathrm{Y}$, modifica la rotulación del producto, indicando que el responsable por su fabricación es la empresa Watts S.A., comercializándolo de esta forma a diversos países (como Filipinas, Indonesia, Guatemala, Rusia y Vietnam) hasta enero de 2008. Como resultado del consumo del suplemento, entre 2007 y 2008 se produce en el país una crisis generalizada de cuadros de hipokalemia severa, alteración que consiste en una disminución relevante de los niveles de potasio en el cuerpo, lo que, dependiendo de cada paciente en concreto, puede generar situaciones de riesgo vital. A pesar de la muerte e intensificación de los cuadros clínicos de muchos consumidores, el tribunal de base no obtuvo convicción acerca de la relación de causalidad con los resultados contra la salud y vida individual, por lo que se descartó su consideración en la atribución de responsabilidad, aplicando solamente los tipos de peligro contra la salud pública regulados en el párrafo 14 del título VI CP55.

\footnotetext{
54 Corte Suprema. 27 de diciembre de 2012. Rol No 6831-2012. "Contra Roberto Oetiker Luchsinger Roberto y otros (Ezzio Aurelio Olivieri Díaz, Egon Arnoldo Hoffman Soto, Juan Cristóbal Costa Contreras, Reinaldo Leonel Torres Pizarro)". pp. 1-2. 
De esta forma, se condenó en primer lugar a W, X e Y por los actos de comercialización de sustancias peligrosas ${ }^{56}$, diferenciando dos períodos a partir del conocimiento acerca de los defectos de la producción. Inicialmente, W y X resultan sancionados por el cuasidelito del art. 317 inc. $\mathrm{II}^{57}$ (en relación con el art. 315 inc. II CP), por la falta de cuidado que significó la ausencia de un adecuado control de calidad sobre el producto comercializado entre junio y noviembre de 2007, hechos calificados en situación de unidad de acción (no especificada). A continuación, se condenó a W, X e Y por el delito del art. 315 inc. $\mathrm{II}^{58}$, en atención a la mantención dolosa del producto en el mercado hasta 2008, hechos que fueron calificados como un delito continuado. Entre ambos conjuntos de realizaciones, se aprecia una relación de concurso real bajo la regla del art. $74 \mathrm{CP}$ que resulta en 800 días y cuatro años de presidio respectivamente, ambas condenas en régimen de libertad vigilada.

En forma secundaria, se condenó a $\mathrm{Y}$ e $\mathrm{Z}$ por los delitos de uso indebido de marca comercial del art. 190 inc. I CP59 y de contrabando propio del art. 168 inc. II del D.F.L. No 30 de 2004 Ministerio de Hacienda ${ }^{60}$ (Ordenanza de Aduanas), por la exportación adulterada del producto defectuoso entre 2007 a 2008, a la pena de 818 días de presidio por aplicación de la regla de concurso medial (art. $75 \mathrm{CP}$ ), a su vez considerado (tal concurso) como unidad de acción bajo la forma de un delito continuado ${ }^{61}$.

Ahora bien, en lo que respecta a la comercialización interna del producto, debe destacarse que el tribunal considera una situación de unidad de acción tanto en el período de realización imprudente (sin explicitar el criterio unificador); como un delito continuado en relación a la etapa dolosa. El querellante recurre de nulidad alegando infracción de derecho por no considerar un concurso real bajo la regla del art. 351 CPP (lo que

56 CS. Rol No 6831-2012, pp. 2-39.

57 Artículo 317 inc. II CP: "Si alguno de tales hechos punibles se cometiere por imprudencia temeraria o por mera negligencia con infracción de los reglamentos respectivos, las penas serán de presidio menor en su grado mínimo o multa de seis a veinte unidades tributarias mensuales".

58 Artículo 315 inc. II CP: "El que efectuare otras adulteraciones en dichas sustancias destinadas al consumo público, de modo que sean peligrosas para la salud por su nocividad o por el menoscabo apreciable de sus propiedades alimenticias, y el que a sabiendas las vendiere o distribuyere, serán penados con presidio menor en su grado máximo y multa de seis a cincuenta unidades tributarias mensuales".

59 Artículo 190 inc. I CP: "El que hiciere poner sobre objetos fabricados el nombre de un fabricante que no sea autor de tales objetos, o la razón comercial de una fábrica que no sea la de la verdadera fabricación, sufrirá las penas de presidio menor en sus grados mínimo a medio y multa de seis a diez unidades tributarias mensuales".

60 Artículo 168 inc. II: "Incurrirá en el delito de contrabando el que introduzca al territorio nacional, o extraiga de él, mercancías cuya importación o exportación, respectivamente, se encuentren prohibidas".

61 CS. Rol No 6831-2012, pp. 54-57. 
implicaría el aumento al menos en un grado de la pena) respecto al período denominado como doloso, dado que a la justificación de la unidad por continuación sostenida no satisfacería los fundamentos materiales requeridos.

Como se ha destacado por la doctrina, en el delito continuado como situación de ampliación de la unidad natural de acción (al límite con el concurso de delitos), esencialmente toda la carga legitimadora gravita en torno al factor subjetivo de unificación ${ }^{62}$. En el caso concreto, el tribunal de base justificó aquel requisito basado en la teoría de la unidad de propósito (o dolo preconcebido), lo que se acreditó mediante la reunión de los imputados en noviembre de 2007, en particular, la planificación asociada al objetivo de mantener el alimento defectuoso en el mercado (como previsión de los actos seriados de comercialización posterior). Ello, a juicio del recurrente, contradice la postura (al parecer mayoritaria) del tribunal en orden a la adopción de la tesis de CuRY, pues en este caso se trataría de beneficiar una situación de preordenación delictiva operando como un (injusto) beneficio al no existir necesariedad en el fraccionamiento en la comisión del delito, sino más bien una planificación (considerando séptimo). Lo interesante del rechazo de la pretensión, es que la Corte evita pronunciarse respecto al fondo del asunto a través del recurso a la situación fáctica acreditada, la que -según se desprende del razonamiento- reflejaría por sí sola una situación de unidad de acción, salvo que se probara necesariamente cada hito procesal para fundamentar un concurso real $^{63}$, lo que indirectamente ratifica la consideración acerca que el delito continuado constituiría un espacio de discrecionalidad judicial para elu-

62 Besio (2012) 118-138.

63 Considerando noveno: "En el caso, no resulta preciso analizar si lo correcto era distinguir la existencia de una unidad de propósito o de las teorias que esgrime el recurrente sobre el fraccionamiento necesario, puesto que de la sola lectura del hecho que se ha tenido por establecido se advierte que los jueces solo discriminaron en la existencia de dos etapas en el desarrollo del delito, una en que se atribuyó actuar negligente a los inculpados y otra, en que se describe un proceder doloso, lo que implicó doble condena a los acusados. Sin embargo, aparte de tal distinción, en el presupuesto fáctico no existe descripción de hechos susceptibles de ser calificados como reiterados, puesto que solo se definieron dos procesos y una serie de personas que resultaron afectados en ellos. La falta de descripción de delitos reiterados impide al tribunal sancionar de esa forma, de modo que carece de toda trascendencia la discusión promovida ya que ninguna influencia podrá tener en lo dispositivo del fallo, lo que resulta suficiente para desechar la causal de nulidad'. CS. Rol No 6831-2012, pp. 23-24. En este sentido, la posición de la CS. asume como requisito implícito para la consideración de un concurso real la fecha exacta de cada acto ejecutivo, contrastando directamente con la sentencia Rol No 3193-2008, la cual en su considerando noveno sostuvo que "la ausencia de exactitudes o precisiones aritmético-cronológicas respecto de la ocurrencia de determinados hechos, no impide al tribunal, que opera en el plano normativo -penal sustantivo y penal adjetivo, apoyado en una realidad fáctica, formarse su intima convicción sobre las características-típicas- de aquellos sucesos (como jurídicamente constitutivos de concurso real)". El paréntesis es nuestro. Corte Suprema. 10 de junio de 2008. Rol No 3193-2008. "Contra Gabriel Ernesto Maldonado López". p. 9. 
dir la regulación concursal, cuyo elemento subjetivo (como núcleo para su admisión) se podría dotar de contenido casi a voluntad ${ }^{64}$.

En segundo lugar, en relación a los actos de exportación adulterada, el tribunal de base califica que los delitos de contrabando propio y uso indebido de marca comercial se encuentran (en cada ocasión de exportación) en relación de concurso medial (art. $75 \mathrm{CP}$ ) y que la repetición de tal conjunción delictiva ${ }^{65}$ constituye un delito continuado ${ }^{66}$. El Servicio Nacional de Aduanas recurre en el mismo sentido que el querellante particular, solicitando se recalifique la situación como un concurso real de delitos. Nuevamente la Corte aplica un razonamiento similar basado en la indeterminación procesal para justificar la unidad de acción que implica el delito continuado ${ }^{67}$.

Lo que se evidencia en ambos conjuntos de imputaciones es la adopción de la teoría del delito continuado como situación ampliada de unidad de acción, aunque desde un punto de vista estrictamente formal, en el sentido de que ni el tribunal de base ni la Corte Suprema son capaces de explicitar el fundamento material que subyace a la identificación del solo elemento subjetivo unificador (más allá de su problemática correspondencia con el dolo típico) como factor suficiente para considerar un simple aumento cuantitativo del injusto (lo que en casos de bienes jurídicos colectivos, admitiría mayor flexibilidad). Tal deficiencia de motivación del razonamiento jurídico, resulta parcialmente encubierto mediante un ejercicio argumentativo (distractor) a partir del presupuesto (implícito) de que ante casos de indeterminación procesal (en un sentido de precisión científica dura), necesariamente debe rechazarse la consideración de un concurso real y apreciarse una situación de unidad de acción. Lo anterior reconduce el problema a la conflictiva distinción (parcialmente inducida en esta sentencia) entre hecho y derecho, la que no puede ser abordada en este contexto, pero que al menos resulta evocativa -en este

64 Jaковs, Günther (1997) Derecho Penal Parte General: Fundamentos y Teoría de la Imputación. 2a Edición. Traducción de Joaquín Cuello Contreras y José Serrano González de Murillo. Madrid: Editorial Marcial Pons. 1013 pp. p. 1094.

65 La apreciación de una situación de unidad o pluralidad de valoración en relación a relaciones concursales ya configuradas, ha sido denominada concurso de concursos, radicándose el problema (no suficientemente tratado por la doctrina en general) en si puede considerarse como unidad (a ser cuantificada bajo un régimen concursal) una pena resultante de la aplicación (previa) de una norma concursal. Este punto excede el propósito de este artículo, pero en tal sentido véase: EscuCHURI (2004) 446-447.

66 CS. Rol No 6831-2012, pp. 54-56.

67 Considerando vigésimo quinto: “Esta pretensión no puede prosperar porque la descripción fáctica no contempla una imputación de hechos que tengan la calidad de reiterados lo que aparece de su simple lectura donde se contempló la comisión por un lapso de tiempo y su remisión a determinados paises, pero sin descripción de contenedores, fechas de exportación, cantidades $u$ otros elementos que hicieran precisa la imputación por hechos acotados y no por una unidad de acción". CS. Rol No 6831-2012, p. 56. 
caso concreto- de que la actividad ilícita realizada mediante la estructura empresarial resultaría muchas veces privilegiada en el sistema penal chileno ${ }^{68}$.

\section{3) CONCLUSIONES DEL ANÁLISIS JURISPRUDENCIAL}

De la revisión de sentencias previamente desarrollada es posible afirmar, a título de conclusión preliminar, que los diferentes supuestos de hecho considerados bajo una situación unidad de acción por la Corte Suprema son: (i) o bien expresamente declarados como delito continuado; o bien (ii) simplemente sancionados bajo el nomen iuris del tipo delictivo aplicable, sin mayor indagación al respecto.

Dicho de otro modo, en aquellos fallos donde no ha existido alegación respecto a la eventual configuración de un delito continuado, ni los intervinientes ni el tribunal aluden a la categoría dogmática de unidad natural de acción. Como bien señala García Alberó, la fisionomía habitual que presentan determinadas agresiones explica el tratamiento esencialmente intuitivo (y no problemático) de la cuestión en la mayor parte de los supuestos y el escaso acceso de la casación o la nulidad de dichas constelaciones, resueltas de entrada como unidad delictiva por los tribunales a quo o de base ${ }^{69}$. Esta tendencia debiera ser resistida a partir del potencial rendimiento práctico, tanto para el órgano persecutor como para la defensa, que una adecuada articulación de tales criterios de unificación presenta de analizar debidamente el factum brutum a subsumir en el contenido jurídico de la acusación (o posterior discusión de fondo), o asimismo como baremo de control sustantivo ante situaciones en que por consideraciones extranormativas de merecimiento de pena (en el sentido de ajenas a las posibilidades sistemáticas de unidad que presenta la tipicidad), el tribunal utiliza aquella indeterminación conceptual antedicha para unificar acciones o configurar concursos.

A partir de todo lo anterior, se han agrupado los supuestos de hecho revisados en tres grupos de análisis, en atención a una sistematización indiciaria que permita evidenciar los criterios (si es que puede hablarse de tales) asumidos por la Corte Suprema en la cuestión desarrollada: (i) consideraciones acerca del concreto merecimiento de pena no formalmente explicitadas; (ii) tratamiento unitario de los delitos contra intereses patrimoniales particulares y; (iii) tratamiento unitario a partir de indeterminación procesal.

\footnotetext{
68 Winter EtCheberry, Jaime (2013) "Derecho Penal e Impunidad Empresarial en Chile". Revista de Estudios de la Justicia. Año 12 Número 19. pp. 91-125. pp. 92-93, 103-104. GARCÍA (1994) 213.
} 


\section{(3.1.)CONSIDERACIONES ACERCA DEL CONCRETO MERECIMIENTO DE PENA NO FORMALMENTE EXPLICITADAS}

En el caso (2) (abuso sexual y producción de pornografía infantil), la diferencia de trato hacia $\mathrm{A}$ (madre de la víctima) respecto de B (conviviente-camarógrafo), en principio pareciera centrarse en que la intervención de propia mano de $\mathrm{A}$ en tres ocasiones en el abuso sexual intensificaría su merecimiento de pena, descargando a $\mathrm{B}$ de tal reproche a título de reiteración. Pero esto evidencia una evidente contradicción: si B no fue castigado como coautor de las tocaciones sucesivas a partir de su falta de intervención en la acción típica (art. 15 No 1 CP), igual consideración debiera extenderse para $A$ respecto a la producción de material pornográfico infantil, siendo castigada con pena de autor a partir de una modalidad de intervención no ejecutiva (reconducible al art. 15 No 1 o bien No $3 \mathrm{CP}$ ). Como se aprecia, no existen razones jurídicas para negar una realización -al menos como delito continuado- de ambos intervinientes respecto a cada contexto situacional tratado como concurso medial, sino más bien consideraciones implícitas de intensificación de un reproche (particularmente moral) sobre la conducta de la madre, excluyendo la aplicación de beneficios de la Ley No 18.216.

Por otra parte, en la causa (11) (caso Adn-Nutricomp), en primer lugar, se asume de entrada una situación unitaria respecto a la realización imprudente del art. 315 inc. II por el primer período de comercialización interna del producto defectuoso. Ciertamente, la constante oscilación acerca de las condiciones de merecimiento de pena de los delitos imprudentes, que varía entre el solo desvalor de conducta (la infracción al deber de cuidado) o el injusto global (resultado lesivo por infracción a deberes de cuidado), facilita la consideración de una situación unitaria a partir del tipo subjetivo como iteración, fundada en una constante falta de atención a la fiscalización del nivel de calidad del producto. Sin embargo ello puede cumplir un rol inverso: una aproximación más detallada al tipo de injusto permitiría haber considerado cada infracción a reglamentos (como regulación extrapenal asociada a los estándares nacionales de producción de alimentos) en relación a los actos de distribución o comercialización, como hito fundamentador de un deber de actualización de la exigencia de cuidado suficientemente plausible para apreciar una relación de concurso real.

En segundo lugar, ahora respecto a la realización dolosa del mismo delito y la exportación fraudulenta del producto, la falta de descripción de los eventos exactos que permitirían individualizar cada hito propio de la reiteración, sirve a la Corte como excusa (procesal) para conservar la calificación jurídica de delito continuado, tras la aguda alegación acerca de la inconsistencia de la justificación subjetiva del constructo 
en la jurisprudencia. En este sentido, el mérito del recurso incoado por el querellante consiste en que tras la invocación de la tesis de CurY, se intenta obtener una declaración formal acerca de la razón que subyace al tratamiento favorable del caso en concreto (a pesar de no satisfacerse tal requisito) ante la (aparente) insuficiencia de los criterios de unidad natural de acción ${ }^{70}$, en un claro (y paradigmático) supuesto de preordenación delictiva (una planificación ¡expresa!), donde constan (formalmente) suficientes hitos demarcatorios para acoger tal pretensión, a partir de la sola valoración del factum brutum prefijado. La sospecha latente de un favorecimiento hacia la delincuencia de cuello blanco, en el sentido de la compatibilidad de la condena con los marcos penales admisibles bajo el régimen de la Ley No 18.216, emerge asimismo a partir de la (discutible) exclusión de la relación causal ${ }^{71}$, circunstancia que de no haber sido descartada, habría habilitado la aplicación del la regla concursal especial del art. 317 inc. I $\mathrm{CP}^{72}$, como lo sostuviera el recurso presentado por la fiscalía.

Nuevamente vinculado al delito continuado, en el caso (3) (delitos tributarios), el tribunal utiliza una argumentación procesal de carácter artificial para, en un sentido inverso al caso previo, agravar la intensidad de la sanción (que de lo contrario no habría superado los tres años y un día de presidio), mediante el rechazo de una situación de unidad delictiva bajo la declaración de que las categorías (dogmáticas) de unidad o pluralidad de delitos constituirían cuestiones de hecho. Adicionalmente a ello, declara que sustantivamente tampoco podría acogerse tal pretensión, en virtud de la regla del inc. III del art. 112 CT que, como se dijo, precisamente cumple la función opuesta: sentar el presupuesto mínimo a partir del cual debería operar una (eventual) unidad por continuación. Lo rescatable de tal aserto para lo que aquí interesa, es que ante la existencia de criterios evidentes a partir de la estructura formal de cada delito, indicativos de la separación entre dos o más realizaciones del tipo, los tribunales tienden a debilitar el fundamento consuetudinario del delito continuado, más allá de que materialmente aquella declaración legislativa solo eviden-

70 No restaría plausibilidad el considerar que la articulación del contenido de injusto del art. 315 inc. II admite la capacidad del bien jurídico (como objeto de naturaleza colectiva e inmaterial) para absorber diversas instancias (en sentido prejurídico) de la acción típica (la autorización -casi automatizada en el contexto de la empresa moderna- para el envío de mercadería a partir de la estructura organizativa en que se insertan W, X e Y) como una sola realización iterada o repetida del tipo.

71 WinTER (2013) 103-104.

72 Artículo 317. "Si la consecuencia de cualquiera de los delitos señalados en los cuatro artículos precedentes, se produjere la muerte o enfermedad grave de alguna persona, las penas corporales se elevarán en uno o dos grados, según la naturaleza y número de tales consecuencias, la multa podrá elevarse hasta el doble del máximo señalado en cada caso". 
cie un aspecto que subyacería igualmente a una adecuada interpretación del sistema de injusto involucrado en cada caso.

Para finalizar esta sección, en el caso (4) (falsificación de instrumentos privados y estafa), se reitera (al igual que en el caso 2) la situación de consideraciones implícitas de merecimiento de pena que son diferenciadas por la comisión de iguales hechos, aspecto evidenciado a partir de las reglas sobre autoría y participación, en beneficio de $\mathrm{Z}$ por su falta de intervención de propia mano en la falsedad previa pero no así en el uso de los documentos falseados, y perjudicando a W, X e Y como autores no ejecutivos en el uso (aplicable al delito de falsedad y a la estafa) pero ejecutores por el forjamiento.

La consideración unitaria de las cuatro estafas (en sentido de actos parciales) de Z (sin explicitar su concreta modalidad) bajo la declaración formal de una situación de reiteración, constituye el talón de Aquiles del fallo, en contraste con el concurso real apreciado sobre los cuatro subconcursos mediales atribuidos a W, X e Z. Ante la existencia de un mismo sujeto pasivo (Isapre Colmena Golden Cross), la estructura de injusto de la estafa admite considerar la fungibilidad de los sujetos instrumentalizados a través del error provocado por el engaño prefabricado, como una sola instancia repetida de defraudación (de estafa en triángulo), predicable de todos los imputados aun cuando (discutiblemente) se considere la absolución de Z por el delito del art. $185 \mathrm{CP}$.

\section{(3.2.)TRATAMIENTO UNITARIO DE LOS DELITOS CONTRA INTERESES PATRIMONIALES PARTICULARES}

Se puede constatar una latente tendencia a considerar en situación de unidad de acción las realizaciones constitutivas de apropiación indebida, estafa y hurto. A nuestro juicio, tal apreciación unitaria deriva del parámetro de cuantificación de la pena a partir de una base económica que resulta común a hurtos y defraudaciones, establecido respectivamente por los arts. 446 (valor de la cosa hurtada) y 467 CP (valor de la cosa objeto de la defraudación), en el sentido de una confusa asimilación entre la determinación de la pena para una sola realización (situación reglada en las disposiciones precitadas) y la acumulación de diversas realizaciones bajo aquel baremo económico (sumando el total de los delitos), lo que significa una interpretación de tales reglas individuales como normas concursales (desconociendo la vigencia de la regla expresa y exclusiva para la reiteración de hurtos del art. $451 \mathrm{CP}^{73}$ ).

\footnotetext{
73 Artículo 451 inciso I: "En los casos de reiteración de hurtos, aunque se trate de faltas, a una misma persona, o a distintas personas en una misma casa, establecimiento comercio, centro comercial, feria, recinto o lugar el tribunal calificará el ilícito y hará la regulación de la pena tomando por base el importe total de los objetos sustraídos, y la impondrá al delincuente en
} 
Solamente en los casos (5) (apropiación indebida de cotizaciones previsionales I) y (9) (apropiación en la pastelería) se aludió a la teoría del delito continuado, castigando las diversas realizaciones según el total del perjuicio patrimonial de acuerdo al art. 467 CP. En este sentido se produce un problema relativo a la determinación de la pena, extrapolable asimismo a los casos (6) (apropiación indebida de cotizaciones II); (8) (apropiación sobre ventas de harina) y (8) (estafa contra leasing industrial) en que se consideró un tratamiento unitario sin referencia explícita, consistente en extrapolar la lógica del art. 451 CP (única regla concursal especial en la materia ${ }^{74}$ ), operación per se constitutiva de analogía perjudicial al imputado ${ }^{75}$. Se trataría entonces de una aplicación por defecto de los tribunales que genera (por la relativa comodidad que entrega aquel baremo cuantitativo) una interpretación forzada de situaciones de unidad de acción (en casos de auténtica reiteración) e ilegal en la determinación de la pena ${ }^{76}$. Esta falta de legalidad en la aplicación de las normas de sanción se evidencia en el caso (10) (hurtos a distribuidora) en que se aplicó directamente la norma del art. $446 \mathrm{CP}$ a diversos actos (no considerados delito continuado) sin alusión al art. $451 \mathrm{CP}$ pero con antecedentes explícitos relativos a una situación de reiteración ${ }^{77}$.

su grado superior". Como se deduce, la regla aplica el sistema de absorción agravada propio del concurso ideal (art. $75 \mathrm{CP}$ ) a una situación de concurso real en vez de las reglas generales para el tratamiento de la reiteración (arts. 74 CP y 351 CPP). Politoff/Matus/RamíREZ (2004) 466. En contra, GARrido sostiene que se trataría de un caso de exasperación en un grado. Garrido (2003) 347.

74 Couso/Hernández (2011) 654.

75 Como apunta GARRIdo (si bien en relación a la utilización de este criterio para la interpretación de la estimación unitaria que exigía el previo art. 509 CDPP), la operación significaría "trasladar o extender el sistema descrito por el art. 451 al señalado por el art. 509 del C.P.P. (lo que) es darle un alcance que no lo tiene, recurriendo a la vía analógica, que la doctrina y la práctica rechazan, particularmente en este caso porque perjudica al procesado y entra en pugna con el art. $19 \mathrm{~N}^{\circ} 3$ de la Constitución”. GarRido (2003) 346. En relación a la situación en España previa la reforma de 1983 (que introdujo la regulación del delito continuado como un régimen concursal sujeto al tratamiento del concurso ideal), se producía idéntica situación que la actual en Chile, lo que era considerado por la doctrina como una vulneración del principio de legalidad, tanto por la creación de un nuevo supuesto de hecho (el compuesto por las sumas individuales de los actos parciales en los delitos patrimoniales) como por la consecuencia jurídica no prevista en la ley (pues al no existir una regla especial referida a la materia -salvo en nuestro medio el art. $451 \mathrm{CP}$ - no se trataría de la pena prevista para el delito que se trate). Choclán Montalvo, José (1997) El Delito Continuado. Madrid: Editorial Marcial Pons. 472 pp. p. 34.

76 En este sentido, normalmente en casos de delitos de baja cuantía, la aplicación de este criterio interpretativo resultará más gravosa que el cálculo de la pena a partir del ilícito más grave (según el art. 351 CPP). Besio (2012) 146.

77 Considerando catorce: "los aspectos cuantitativos de lo sustraido, factor que solo toma importancia para la determinación de la pena, como lo indica el artículo 446 del Código Penal (...) y el castigo mayor se expresa cuando lo hurtado excede de cuatrocientas unidades tributarias mensuales. En el hecho investigado y en relación al dinero sustraido, las tres cantidades consideradas en las resoluciones referidas por el recurrente exceden de esa cifra". CS. Rol No 7777-2011, pp. 21-22. 
Si por el contrario, tal apreciación unitaria no se vincula a una determinada forma de castigar la reiteración sino que al método que los tribunales se ven constreñidos para determinar la pena de una situación de unidad de acción (sea delito continuado o realización iterativa del tipo), puesto que la penalidad de los actos sucesivos muchas veces dependerá de la contingencia del perjuicio ocasionado, no existiendo un único marco penal aplicable ante realizaciones que, pese a constituir un aumento cuantitativo del mismo injusto, por el sistema legal de determinación de la pena aparecen como diversas acciones, se trataría de un problema de lege ferenda insalvable a través de la sola interpretación.

\section{(3.3.)TRATAMIENTO UNitARio A PARTIR DE INDETERMiNACIÓN PROCESAL}

Sobre la base de los razonamientos contenidos en la causa (1) (estupro) (considerando sexto) y el caso (11) (Adn-Nutricomp) (considerando noveno), resulta posible afirmar que para la Corte existiría una correlación entre el déficit de prueba respecto a la individualidad fáctico-temporal de cada acto ejecutivo con la configuración de un delito continuado ${ }^{78}$, señalando expresamente que ante una situación inversa, correspondería la apreciación de un concurso real. Sin embargo esta declaración no pasa de un aserto meramente nominal, pues como se vio particularmente en los casos (2) (respecto a Y sobre su intervención como camarógrafo) y (4) (en cuanto al tratamiento unitario respecto de $\mathrm{Z}$ a pesar de cuatro hitos exactamente individualizados), la determinación procesal no constituye necesariamente reiteración.

Bajo la constatación básica de que la aplicación del derecho requiere de un factum brutum a partir del cual efectuar la operación de subsunción, no puede aceptarse que la falta de tal sustrato repercuta sustantivamente en perjuicio del imputado a través de la construcción jurisprudencial de una función adjetiva. Delito continuado y reiteración suponen la acreditación de una pluralidad de actos que serán estimados como un solo hecho o varios hechos acorde a las valoraciones jurídicas de rigor. Por ende el recurso a un problema de suficiencia probatoria en (1) y (11) no puede sino interpretarse como la concreción jurídica de un cúmulo de valoraciones extranormativas (en el sentido de su falta de adecuación a la reconstrucción de la ley penal), contradictorias a un concepto mínimamente aceptable la adjudicación como función de atribución de responsabilidad juridica.

\footnotetext{
78 Lo que también se evidencia en la jurisprudencia reciente (en general): BEsıo (2012) 138141 .
} 


\section{4) Consideraciones Finales (A Título dE COROLARIO)}

Ante el relativo consenso acerca de los (no por ello menos dúctiles) requisitos de configuración de un delito continuado, no se puede predicar idéntica claridad en los casos de unidad natural de acción en su modalidad de realización iterativa, la que resulta implícitamente asimilada al delito continuado sin que (aparentemente) exista en la praxis mayor abundamiento respecto a los elementos que permiten ampliar cuantitativamente la realización formal del tipo. Esta constatación no deja de ser relevante desde el momento en que una adecuada construcción argumentativa, ligada a la articulación del tipo de injusto, no se ve expuesta (al menos en el mismo nivel de intensidad) a los reparos que admite en general la teoría del delito continuado, sea cual sea la concreta manifestación teórica que se defienda del mismo en el caso concreto.

Por otro lado, la difusa conceptualización en la praxis judicial de la teoría de la unidad de acción (en sentido amplio), facilita su utilización más allá de su concreta función dogmática como parámetro de merecimiento de pena centrado en la relación de lesividad de las conductas enjuiciadas, en el sentido de operar como un baremo judicial de medición de pena de carácter contingente, mediante la consideración de factores en variadas ocasiones propios de la individualización judicial de la pena, algunas veces de manera favorable y otras perjudicial para las respectivas pretensiones de los intervinientes. Lo anterior, se ve intensificado por la elusión de las alegaciones materiales tendientes a poner de relieve tal distorsión, mediante argumentos en clave adjetiva por el tribunal, cuyo predicado de supremo viene a zanjar definitivamente la cuestión en virtud de su función como última oportunidad de revisión institucional (al menos en el sistema recursivo tradicional). 